\title{
LI. Notice respecting certain changes of colour in the choroid coat of the eyes of animals
}

\author{
Sir David Brewster LL.D. F.R.S.
}

To cite this article: Sir David Brewster LL.D. F.R.S. (1833) LI. Notice respecting certain changes of colour in the choroid coat of the eyes of animals, Philosophical Magazine Series 3, 3:16, 288-289, DOI: $10.1080 / 14786443308648179$

To link to this article: http://dx.doi.org/10.1080/14786443308648179

册 Published online: 01 Jun 2009.

Submit your article to this journal $₫$

Џ Article views: 2

Q View related articles $₫$ 
point whose coordinates in that plane are $x$ and $y$, is ascertained to come under the formula

$$
\frac{\mathrm{C}}{1+\mathrm{A} x+\mathrm{B} y},
$$

$A, B$ and $C$ being constants, dependent upon the number and positions of the points of support, and upon the forces impressed upon the system.

From this formula it follows, that there is a certain line, distant from the origin by a quantity equal to $\frac{1}{\sqrt{\mathrm{A}^{2}+\mathrm{B}^{2}}}$, and inclined to the axis of $x$ at an angle whose tangent is $\frac{A}{B}$; about which the moments of all the pressures are the same. This line may be properly called the axis of least pressure, as the principle whence its existence and properties have been deduced, may be designated the principle of least pressure.

Where the points of support are in the same line, this axis resolves itself into a point; and it follows that the moments of the resistances about a certain point in the line in which they act, are all equal; - - a result which is verified by the known conditions of the pressure upon two points of support.

LI. Notice respecting certain Changes of Colour in the Choroid Coat of the Eyes of Animals. By Sir David Brewster, LL.D. F.R.S.

IN the Number of this Journal for August last, (p. 87) Mr. Fielding has published some interesting experiments respecting certain changes of colour induced by chemical and other agents on the membrane lining the choroid coat of the eye; and he has particularly described an experiment which shows that when the colours have disappeared by drying, they may be revived by simple immersion in water.

In the chapter on the colours of natural bodies in the article Optics in the Edinburgh Encyclopædia, I have brought forward this fact as illustrating and supporting Sir Isaac Newton's Theory of the Colours of Natural Bodies, and I am induced to mention this at present, not only for the purpose of giving to Dr. Drummond of Belfast, the merit of having first made this curious experiment, but also of making some further observations upon it in reference to its connexion with the theory of Newton. The following is the passage in which it is mentioned.

"Dr. Drummond of Belfast observed, that the membrane 
behind the retina of the dog, and other animals which produce those blue and green and sometimes red reflections, which often shine with such brilliancy in the living animal, loses the power of reflecting these tints when it is dry, and becomes entirely black. Upon learning this fact from Dr. Drummond, we prepared several eyes that reflected these colours with great vivacity, and invariably found that they became black when $d r y$, and blue and green when softened with water. After some of them had remained four or five years in a dry state, they still possessed the property of developing their colours by moisture. It is worthy of remark, that the black passed instantly into a brilliant blue, the blue into green, and the green into a greenish yelloro*."

After this paragraph was written, I had occasion to repeat the experiment on one of the eyes just mentioned, and I found that the colours could be revived in the membrane ten or twelve years after it had been taken from the anima!.

I do not recollect to have anywhere seen it stated that the brilliant colours which appear in the eyes of animals have been noticed in the human eye; but $I$ had orcasion many years ago to observe them in the most distinct manner, and to examine them repeatedly in the eye of a boy about ten years of age. The colour was a bright red, with a purplish tinge; but it is not in my power to ascertain now whether or not this colour varied with an increase of years. On this point Mr. Fielding remarks, "As regards the human eye, I have had very little opportunity for investigation; and though I have proved its [the new membrane's] existence, I cannot say that it ever presented any distinctly coloured appearance."

Having just succeeded in finding one of the prepared specimens of the tapetum of an ox's eye, mentioned in a preceding paragraph, and which has been preserved for nearly twenty years, I find that when dry, it is as black as charcoal ; and that the blue and green colours of the membrane above referred to, could be revived in all their original brightness by immersion in water.

It is a curious circumstance in the colours thus produced, that though they are apparently those of thin plates, they advance immediately from black to blue and green of the second order, all the intermediate colours of the first order being omitted. The same phænomenon occurs in the peacock's tail, in the plumage of different birds, and in Labrador felspar. In another communication I hope to be able to give a satisfactory explanation of this remarkable interruption of continuity.

Belleville, by Kingusie, Sept. 18, 1833.

* Edinb. Encycl. vol. xv. p. 623.

Third Series. Vol. 3. No. 16. Oct. 1833. 